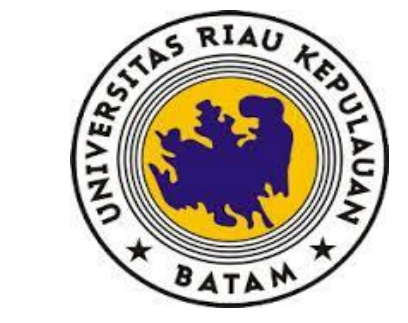

Available online at www.journal.unrika.ac.id

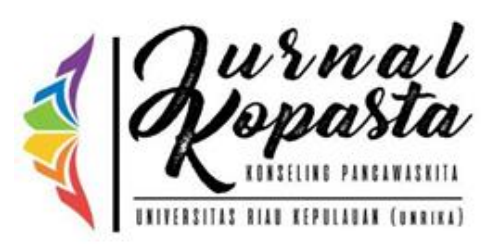

\title{
EFEKTIFITAS LAYANAN INFORMASI TERHADAP PENANGGULANGAN VERBAL BULLYIING DI TAMAN PENDIDIKAN AL-QUR'AN AL-MI'RAJ BATAM
}

(EFFECTIVENESS OF INFORMATION SERVICES ON VERBAL BULLYIING AT TAMAN PENDIDIKAN AL-QUR'AN AL-MI'RAJ BATAM)

\author{
Tamama Rofiqah * \& Fitri Handayani \\ ${ }^{a}$ Division of Counseling and Guidance, University, of Riau Kepulauan, Batam
}

\begin{abstract}
ABSTRAK
Penelitian ini bertujuan untuk mengungkapkan efektifitas layanan informasi terhadap penanggulangan verbal bullying di Taman Pendidikan Al-Qur'an Batam. Jenis penelitian ini adalah penelitian kuantitatif dengan pendekatan pre eksperimen desaign, untuk menguji apakah layanan informasi dapat menanggulangi perilaku verbal bullying. Teknik pengambilan sampel penelitian dengan menggunakan sample jenuh yaitu seluruh siswa Taman Pendidikan Al-Qur'an yang berusia 13-14 tahun. Pengumpulan data menggunakan Skala Likert, kemudian dianalisis dengan menggunakan uji-t. Temuan penelitian yang diperoleh adalah layanan informasi efektif dalam menanggulangi verbal bullying di Taman Pendidikan Al-Qur'an Batam. Dengan perolehan skor Z untuk uji dua sisi adalah -3.412 dengan taraf signifikansi 0.01, maka Ho ditolak dan Ha diterima.
\end{abstract}

Kata Kunci: Layanan Informasi, Verbal Bullying

\section{ABSTRACT}

This study aims to reveal the effectiveness of information services against verbal bullying in Taman Pendidikan Al-Qur'an Batam. This type of research is quantitative research with preexperiment approach desaign, to test whether information service can overcome verbal bullying behavior. The research sampling technique using saturated samples is all students of the Taman Pendidikan Al-Qur'an aged 13-14 years. Data collection using Likert Scale, then analyzed by using t-test. The research findings obtained are the effecve information service in tackling verbal bullying in Taman Pendidikan Al-Qur'an Batam. With the acquisition of Z score for the two-sided test is -3.412 with a significance level of 0.01 , Ho is rejected and $\mathrm{Ha}$ is accepted.

Keywords: Information Services, Verbal Bullying 
Tamama Rofiqah dan Fitri Handayani / Jurnal Kopasta 5 (1), (2018) 14 - 22

\section{PENDAHULUAN}

Fenomena bullying di lingkungan sekolah di Indonesia saat ini begitu memprihatinkan. Hal ini dibuktikan dengan data dari Komisi Nasional Perlindungan Anak, bahwa tahun 2011 menjadi tahun dengan tingkat kasus bullying tertinggi di lingkungan sekolah yaitu sebanyak 139 kasus kekerasan dan 82 diantaranya meninggal dunia (Komnas PA, 2011). Olweous (dalam Karina 2013) mengungkapkan beberapa karakteristik pelaku bullying, diantaranya adalah memiliki sikap positif terhadap kekerasan, implusif, ingin mendominasi orang lain dan kurang memiliki rasa empati. Bullying telah menjadi masalah global terutama di sekolah, bullying dalam bahasa Inggris berasal dari kata bully yang berarti menggertak atau mengganggu orang yang lemah. Sejiwa (dalam Fatimah Ayu 2016) bullying adalah perbuatan negatif yang dilakukan dengan sengaja dan burulang-ulang untuk menyerang orang lain yang lemah dan tidak bisa membela diri sendiri. Robiah Flora (2004) Bullying merupakan perilaku agresif dan negatif sejumlah orang atau seseorang secara berulang kali yang menyalahgunakan ketidakseimbangan kekuatan dengan tujuan menyakiti targetnya (korban) secara mental atau secara fisik.

Budaya bullying (kekerasan) atas nama senioniritas masih sering terjadi dikalangan peserta didik. Bullying adalah suatu bentuk kekerasan anak yang dilakukan teman sebaya kepada seorang (anak) yang lebih rendah atau lebih lemah untuk mendapat keuntungan atau kepuasan tertentu. Biasanya bullying terjadi berulang kali bahkan ada yang dilakukan secara sistematis. Bullying dapat berbentuk fisik, verbal ataupun psikologis, serta dapat dilakukan secara langsung maupun tidak langsung, hal ini sering sekali dilakukan beberapa kali bahkan dengan korban yang sama (Wisnu Sri Hartinjung, 2014).

Perilaku bullying akan memberi dampak bagi semua pihak yang terlibat dalam perilaku bullying tersebut, namun yang akan mengalami dampak yang lebih serius adalah para korbannya, dampak fisik yang dirasakan korban berupa luka memar, kerusakan otak, luka bakar dan bahkan kematian. sedangkan dampak bullying secara psikologis seperti rendahnya harga diri korban, ketidak mampuan berhubungan dengan orang lain, kemudian dampak bullying secara kejiwaan adalah depresi, kecemasan yang berlebihan dan beresiko tinggi bunuh diri. (Rigby dalam Wisnu Sri Hartinjung, 2014)

Berdasarkan studi pendahuluan dan wawancara yang dilakukan kepada salah satu guru di Taman Pendidikan Al-Qur'an Al-Mi'raj Batam adalah ditemukan siswa remaja yang melakukan bullying setiap hari di kelas malam tersebut. Bullying yang dilakukan 
Tamama Rofiqah dan Fitri Handayani / Jurnal Kopasta 5 (1), (2018) 14 - 22

tiap hari oleh siswa kelas malam tersebut adalah verbal bullying seperti mengejek teman sekelasnya dengan sindiran, warna kulit, makian, penghinaan, memanggil dengan panggilan yang tidak pantas, dan bahkan pekerjaan orang tuanya, hal itu dilakukan tiap hari bahkan dalam proses pembelajaranpun juga dilakukan. Adapun perilaku bullying fisik hal ini terjadi apabila peserta didik melakukan perlawanan sehingga terjadinya perkelahian.

Dengan kasus bullying yang banyak terjadi di sekolah-sekolah perlu dilakukan upaya dalam mencegah dan mengatasi perilaku verbal bullying yaitu dengan mengupayakan pemberian layanan informasi dimana layanan tersebut memberikan wawasan dan pemahaman mengenai bullying, bentuk-bentuk bullying, dampak dari bullying dan halhal lainnya yang berkaitan dengan bullying. layanan informasi adalah layanan dalam bimbingan dan konseling yang memungkinkan peserta didik menerima dan memahami berbagai informasi dibidang pribadi, sosial, belajar dan karir yang dapat dipergunakan untuk mengenal diri dan lingkungannya, yang nantinya dengan pemahaman yang tepat tersebut peserta didik dapat memecahkan permasalahan yang dihadapi dan mencegah halhal yang berpengaruh buruk pada dirinya.

Adapun rumusan masalah dalam penelitian ini adalah: Bagaiamana perilaku verbal bullying sebelum diberikan perlakuan? Bagaimana perilaku verbal bullying setelah diberikan perlakuan? Dan apakah efektif layanan informasi dalam menanggulangi perilaku verbal bullying di Taman Pendidikan Al-Qur'an Al-Mi'raj Batam?

Maka tujuan penelitian ini adalah untuk mengetahui efektifitas layanan informasi dalam menanggulangi perilaku bullying di Taman Pendidikan Al-Qur'an Batam sebelum dan sesudah diberikannya layanan.

\section{LANDASAN TEORI}

\section{Layanan Informasi}

Prayitno \& Erman Amti (2004), layanan informasi adalah layanan bimbingan dan konseling yang memungkinkan siswa menerima dan memahami berbagai informasi yang dapat digunakan sebagai bahan pertimbangan dan pengambilan keputusan untuk kepentingan peserta didik. Layanan informasi merupakan perwujudan dari fungsi pemahaman pelayanan bimbingan dan konseling, lebih jauh lagi layanan informasi akan dapat menunjang pelaksanaan fungsi-fungsi bimbingan konseling lainnya dalam kaitan antara bahan informasi dengan permasalahan individu 
Tamama Rofiqah dan Fitri Handayani / Jurnal Kopasta 5 (1), (2018) 14 - 22

Menurut Prayitno \& Erman Amti (2004) pada dasarnya jenis dan jumlah informasi tidak terbatas. Namun, khusunya dalam rangka pelayanan bimbingan dan konseling, hanya akan dibicarakan tiga jenis informasi, yaitu (a) informasi pendidikan, (b) informasi pekerjaan, (c) informasi sosial budaya.

Layanan informasi dapat dilakukan dengan menggunakan beberapa metode yang ada dapat juga dengan menggunakan bimbingan klasikal. Layanan informasi yang disampaikan atau jenis kegiatan bimbingan yang dilakukan dengan bimbingan klasikal dapat menjangkau sejumlah siswa secara merata para siswa sekelas dapat menerima informasi yang sama demikian dapat meminimalkan pemahaman yang keliru atau kesalahan persepsi

\section{Bullying}

Coloroso Barbara (dalam Rizki Prihatin dkk, 2016) menyatakan bahwa Bullying merupakan aktivitas sadar, disengaja, dan bertujuan untuk melukai, menanamkan ketakutan melalui ancaman agresi lebih lanjut, dan menciptakan teror yang didasari oleh ketidak seimbangan kekuatan, niat untuk mencederai, ancaman agresi lebih, teror yang dapat terjadi jika penindasan peningkatan tanpa henti. Adapun bentuk bullying terdiri dari tiga yaitu Overt bullying (intimidasi secara terbuka), Indirect bullying (intimidasi secara tidak langsung) dan Cyberbullying (intimidasi memanfaatkan teknologi) yang sering digunakan pada umumnya oleh pelaku bullying tersebut, (Bauman dalam Fitrian Saifullah, 2016). Terdapat tiga jenis bulling yaitu bullying fisik, bullying verbal, dan bullying mental atau psikologis (sejiwa, 2004).

Menurut Priyatna (dalam Ade Novera Prahardika, 2014) Dampak buruk yang dapat terjadi pada anak yang menjadi korban tindakan bullying, antara lain : 1) Kecemasan,

2) Merasa kesepian, 3) Rendah diri, 4) Tingkat kompetensi sosial yang rendah, 5) Depresi, 6) Simtom psikosomatik, 7) Penarikan sosial, 8) Keluhan pada kesehatan fisik, 9) Kabur dari rumah, 10) Penggunaan alkohol dan obat, 11) Bunuh dari dan 12) Penurunan performasi akademik.

\section{METODE PENELITIAN}

Jenis penelitian yang digunakan dalam penelitian ini adalah penelitian kuantitatif. Metode yang digunakan dalam penelitian ini adalah penelitian ekperimen dengan cara 
Tamama Rofiqah dan Fitri Handayani / Jurnal Kopasta 5 (1), (2018) 14 - 22

memberikan perlakuan melalui layanan informasi kepada subjek penelitian. Adapun desain penelitian ini adalah:

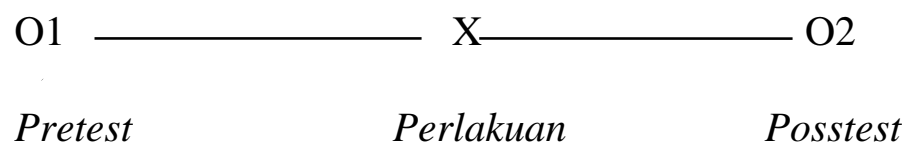

Gambar 1. Desain Penelitian (Sugiyono 2014)

\section{Keterangan}

$\mathrm{O} 1=$ kelompok eksperimen dengan diberikan pretest sebelum diberikan perlakuan, pretest untuk mengukur kondisi awal responden sebelum diberikan perlakuan.

$\mathrm{X}=$ Diberikan perlakuan pada kelompok eksperimen.

$\mathrm{O} 2=$ Hasil setelah diberikan perlakuan dan kemudian diberikan posttest .

Pengambilan sampel dalam penelitian ini menggunakan teknik Sampling Jenuh. Sampling Jenuh adalah tekhnik penentuan sampel dengan menggunakan semua anggota populasi yang digunakan sebagai sampling dengan populasi sebanyak 15 orang. Adapun tekhnik pengumpulan data yang digunakan pada penelitian ini adalah dengan menggunakan angket. Untuk menjawab rumusan masalah digunakan analisis dengan tekhnik wilcoxon signed ranks test pengujian dilakukan menggunakan taraf signifikan 0,05, dengan kriteria keputusan dari uji wilcoxon signed ranks test, jika nilai signifikan $>0,05$, maka Ho diterima, dan jika nilai signifikan $<0,05$, maka Ho ditolak.

\section{HASIL PENELITIAN}

Deskripsi data penelitian ini digunakan untuk memperoleh gambaran secara rinci mengenai distribusi data verbal bullying siswa, maka data pretest dan posttest akan disajikan sebagai berikut :

Tabel I. distribusi skor Pretest dan Posttest

\begin{tabular}{|l|l|l|l|l|l|l|}
\hline NO & \multicolumn{3}{|c|}{ Pretest } & \multicolumn{3}{c|}{ Postest } \\
\cline { 2 - 6 } & Nama & Skor & Kategori & Nama & Skor & Keterangan \\
\hline
\end{tabular}


Tamama Rofiqah dan Fitri Handayani / Jurnal Kopasta 5 (1), (2018) 14 - 22

\begin{tabular}{|c|c|c|c|c|c|c|}
\hline 1. & KA & 68 & Sedang & KA & 80 & Sangat tinggi \\
\hline 2. & HY & 67 & Sedang & HY & 80 & Sangat tinggi \\
\hline 3. & ZK & 73 & Tinggi & ZK & 82 & Sangat tinggi \\
\hline 4. & LS & 75 & Sangat tinggi & LS & 80 & Sangat tinggi \\
\hline 5. & IM & 76 & Sangat tinggi & IM & 77 & Sangat tinggi \\
\hline 6. & MF & 59 & Sangat rendah & MF & 75 & Sangat tinggi \\
\hline 7 & CO & 59 & Sangat rendah & CO & 78 & Sangat tinggi \\
\hline 8. & ZF & 59 & Sangat rendah & ZF & 83 & Sangat tinggi \\
\hline 9. & ST & 60 & Rendah & ST & 73 & Tinggi \\
\hline 10. & AH & 62 & Rendah & AH & 75 & Sangat tinggi \\
\hline 11. & FS & 63 & Rendah & FS & 80 & Sangat tinggi \\
\hline 12. & DA & 67 & Sedang & DA & 75 & Sangat tinggi \\
\hline 13. & AT & 59 & Sangat rendah & AT & 78 & Sangat tinggi \\
\hline 14. & ZN & 59 & Sangat rendah & ZN & 79 & Sangat tinggi \\
\hline 15. & TR & 75 & Sangat tinggi & TR & 83 & Sangat tinggi \\
\hline & & 981 & & & 1173 & \\
\hline
\end{tabular}

Berdasarkan tabel diatas dapat dijelaskan bahwa seluruh siswa mengalami peningkatan perubahan perilaku verbal bullying setelah diberikannya layanan informasi.

Sebelum analisis data dilakukan, maka terleih dulu akan dilakukan uji prasyarat analisis.

\section{Uji Normalitas.}

Dalam penelitian ini digunakan uji normalitas statistik Shapiro-wilk, dengan kriteria pengujian jika probabilitas $\geq 0,05$ maka data berdistribusi normal jika nilai sig <0,05 maka data tidak berdistribusi normal.

Adapun hasil perhitungan normalitas statistik versi 20 for windows dapat dilihat pada tabel berikut ini.

Tabel II Hasil Uji Normalitas Pretest dan Posttest

Tests of Normality

\begin{tabular}{|c|c|c|c|c|c|c|}
\hline \multirow{2}{*}{} & \multicolumn{3}{|c|}{ Kolmogorov-Smirnov ${ }^{\mathrm{a}}$} & \multicolumn{3}{c|}{ Shapiro-Wilk } \\
\cline { 2 - 7 } & Statistic & Df & Sig. & Statistic & Df & Sig. \\
\hline
\end{tabular}


Tamama Rofiqah dan Fitri Handayani / Jurnal Kopasta 5 (1), (2018) 14 - 22

\begin{tabular}{|l|l|l|l|l|l|l|} 
Pretest & .192 & 15 & .142 & .836 & 15 & .011 \\
\hline
\end{tabular}

a. Lilliefors Significance Correction

Tests of Normality

\begin{tabular}{|l|r|r|r|r|r|c|}
\hline & \multicolumn{3}{|c|}{ Kolmogorov-Smirnov $^{\mathrm{a}}$} & \multicolumn{3}{c|}{ Shapiro-Wilk } \\
\cline { 2 - 7 } & Statistic & \multicolumn{1}{c|}{$\mathrm{df}$} & \multicolumn{1}{c|}{ Sig. } & Statistic & \multicolumn{1}{c|}{ Df } & \multicolumn{1}{c|}{ Sig. } \\
\hline postest & .150 & 15 &, 200 & .944 & 15 & .429 \\
\hline
\end{tabular}

${ }^{*}$. This is a lower bound of the true significance.

a. Lilliefors Significance Correction

Berdasarkan tabel normalitas di atas, maka dapat dilihat bahwa pada pretest data berdistribusi tidak normal dengan sig $=.011$ artinya data pretest berdistribusi tidak normal .0011 > 0,05 dan pada tabel posttest data berdistribusi tidak normal dengan sig $=.429$, artinya data posttes berditriusi tidak normal $.429 \geq 0,05$.

\section{Uji Hipotesis}

Untuk menguji hipotesis menggunakan uji non parametric dengan menggunakan wilcoxon signed rank dengan menggunakan SPSS 20, penggunaan statistic non parametric berdasarkan kriteria sampel yang kurang dari 30 orang. Uji wilcoxon digunakan untuk menganalisis hasil pengamatan yang berpasangan dari dua data apakah data tersebut berbeda atau tidak.

Adapun hipotesis yang diajukan dalam penelitian ini adalah

Ha: terdapat efektifitas layanan informasi terhadap penanggulangan perilaku verbal bullying

Ho: tidak terdapat efektifitas layanan informasi terhadap penanggulangan perilaku verbal bullying

Adapun keriteria keputusan pengujian hipotesis adalah sebagai berikut

1. Tolak Ho dan diterima Ha, bila probabilitas signifikan ( Alpha $\leq 0,05$ )

2. Tolak Ho dan Ha, bila probabilitas signifikan ( Alpha $\geq 0,05$ )

Pengujian hipotesis menggunakan wilcoxon signed rank test melalui program SPSS 20, adapun hasil yang diperoleh dari perhiungan tersebut adalah : 


\section{Tabel III Hipotesis}

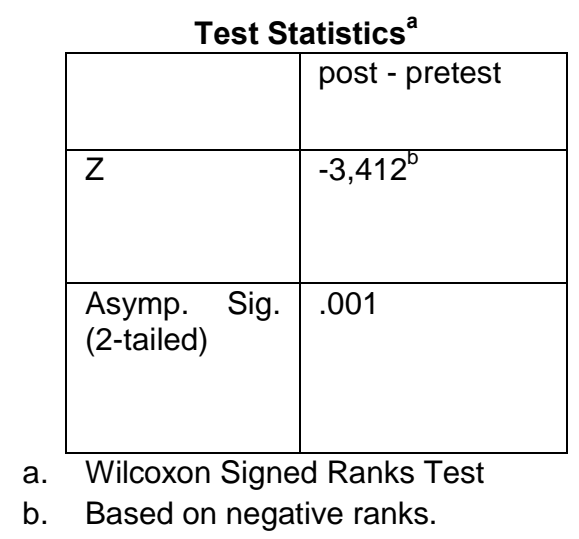

Berdasarkan tabel diatas dapat dilihat bahwa skor $\mathrm{Z}$ untuk uji dua sisi adalah 3.412 dengan signifikasi -0.01, maka Ho ditolak dan Ha diterima, ini berarti bahwa terdapat perbedaan yang signifikan pada perilaku bullying siswa yang telah diberikan perlakuan, dari uraian tersebut dapat menjawab hipotesis berbunyi "Efektifitas layanan informasi terhadap penanggulangan perilaku verbal bullying Siswa”.

\section{PEMBAHASAN DAN SARAN}

1. Gambaran verbal bullying siswa sebelum diberikan layanan informasi.

Berdasarkan hasil penelitian diketahui bahwa pretest verbal bullying siswa adalah terdapat siswa yang termasuk ke dalam katagoi sangat tinggi 3 orang yaitu siswa yang termasuk katagori tinggi sebanyak 1 orang, siswa yang katagori sedang sebanyak 3 orang, siswa yang katagori rendah sebanyak 3 orang dan siswa yang katagori sangat rendah sebanyak 5 orang.

2. Gambaran verbal bullying siswa setelah diberikan layanan informasi.

Berdasarkan hasil penelitian diketauhi bahwa posttest verbal bullying siswa setelah diberikan layanan informasi mengalami peningkatan, sehingga dapat dikatakan bahwa layanan informasi efektif dalam menanggulangi perilaku verbal bullying siswa.

3. Pembelajaran karakter efektif dalam menanggulangi perilaku bullying siswa

Berdasarkan hasil penelitian, layanan informasi efektif dalam menanggulangi perilaku verbal bullying siswa, ini terlihat dari pretest dan posttest. Dan layanan 
Tamama Rofiqah dan Fitri Handayani / Jurnal Kopasta 5 (1), (2018) 14 - 22

informasi ini membei pengaruh yang signifikan terhadap penaggulangan verbal bullying siswa, hal ini terlihat dari angket yang diberikan sebelum diberikan layanan informasi sangat rendah dan setelah diberikan perlakuan meningkat.

Dari hasil penelitian, pembahasan, dan kesimpulan diatas maka peneliti mengajukan beberapa saran sebagai berikut:

1. Bagi Guru

Diharapkan agar setiap melakukan proses belajar mengajar diharapkan agar guru dapat memberikan atau mengingatkan kepada siswa tentang dampak perilaku dari verbal bullying.

2. Bagi Siswa

Siswa yang telah mengikuti pemberian layanan informasi dasarankan untuk dapat mencegah terjadinya verbal bullying.

\section{DAFTAR PUSTAKA}

A.Muri Yusuf. (2013). Metodologi Penelitian: UNP Prees.

Ade, Novera Prahardika. (2014). Upaya Meningkatkan Pemahaman Bahaya Bullying Melalui Bimbingan Klasikal Pada Siswa. Universitas Ahmad Dahlan.

Fitrian, Saifullah. (2016). Hubungan Antara Konsep Diri Dengan Bullying Pada Siswa-Siswa SMP Negeri 16 Samarinda. Jurnal Psikilogi.

Karina, dkk. (2013) Perilaku Bullying Dan Karakter Remaja Serta Kaitannya Dengan Karakteristik Keluarga dan Peer Group. Jurnal Ilmu Keluarga dan Konsumen.

Komnas PA Tahun 2011. Bullying di Sekolah 139 kasus (29 juni 2012).detikNews.

Prayitno \& Erman Atmi. (2004). Dasar-dasar Bimbingan dan Konseling. Jakarta: Rineka Cipta.

Rizki Prihatin dkk. (2016). Penggunaan Tekhnik Role Playing Untuk Mengurangi Perilaku Bullying Siswa Kelas XII MIA SMA Negri 5 Palu. Jurnal Konseling \& psikoedukasi.

Robiah,Flora. (2014). Mengurangi Perilaku Bullying Kelas X-4 Melalui Pemberian Layanan Bimbingan Kelompok Teknik Role Playing di SMA Negri 12 Medan Tahun Ajaran 201-2014. Jurnal Seintech.

Sugiyono.(2014). Metode Penelitian Kuantitatif, Kualitatif, R\&D. Bandung: Alfabeta.

Wisnu Sri Hartinjung. (2015). Profil Pelaku dan Korban Bullying di Sekolah Dasar. Universitas Muhammadiyah Surakarta. Jurnal. 